Çukurova Üniversitesi Mühendislik Mimarlık Fakültesi Dergisi, 31(1), 381-393 ss., Haziran 2016

Çukurova University Journal of the Faculty of Engineering and Architecture, 31(1), pp. 381-393, July 2016

\title{
Elazığ Bölgesi Kromitit ve Yan Kayaçlarına ait PGE İçerikleri ve Jeokimyasal Yorumu
}

\author{
Gülşah ÖZEK ${ }^{* 1}$, Muharrem AKGÜL ${ }^{2}$, Nusret NURLU ${ }^{3}$, Nil YAPICI ${ }^{4}$

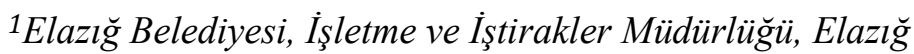 \\ ${ }^{2}$ Fırat Üniversitesi, Mühendislik Fak., Jeoloji Mühendisliği Bölümü, Elazı̆̆ \\ ${ }^{3}$ Çukurova Üniversitesi, Mühendislik-Mimarlık Fak., Jeoloji Mühendisliği Bölümü, Adana \\ ${ }^{4}$ Çukurova Üniversitesi, Mühendislik-Mimarlık Fak., Maden Mühendisliği Bölümü, Adana
}

Geliş tarihi: 08.02.2016 Kabul tarihi: 28.03.2016

\section{Özet}

Çalışma alanında, dünit ve kromitit içeren harzburjitlerden oluşan tektonitler ile dünit, verlit, klinopiroksenit, gabrolardan oluşan kümülatlar ve tüm bu birimleri kesen tekil diyabaz daykları, levha dayk karmaşığı ve bazik volkanik kayaçlar bulunmaktadır. Ayrıca kayaç ve kromit örneklerinden Pt, Pd, $\mathrm{Rh}$ ve Au için ICP-MS yöntemi ile, Ir ve kromitlerin iz element içerikleri ise Nötron Aktivasyon yöntemi ile analiz edilmiştir. analiz sonuçları ilksel manto değerlerine göre normalleştirmiş ve sonuçlar spider diyagramlarında değerlendirilmiştir. Buna göre kayaçlarda; Rh negatif bir anomali gösterip mantoya göre fakirleşmekte, Pt mantoya yakın ve mantoya göre fakirleşmekte, Pd mantoya yakın mantoya göre zenginleşmekte olup Au ise yine mantoya göre zenginleşmektedir. Ir oranı 45-440 arasında değişmekte, Rh oranı 0,05-5,56 arasında ve Pt oranı ise 0,1 ile 23 arasındadır ve örneklerin Irarsit olduğu, kromitlere ait $\mathrm{Pd} / \mathrm{Ir}$ 'e karşı $\mathrm{Pt} / \mathrm{Pt}^{*}$ verilerine göre ise astenosferik komposizyona sahip oldukları belirlenmiştir.

Anahtar kelimeler: Guleman, Ofiyolit, Kromit, PGE (platin grubu elementler), Elazı $\breve{g}$

\section{Platin Group Elements (PGE) Contents and Interpretation Geochemistry of Chromite Deposits with Host Rocks in Guleman (Elazığ) Region}

\begin{abstract}
Guleman ophiolite made up of tectonites which comprises dunite and chromite bearing harzburgites and cumulates which contain dunites, wehrlite, clinopyroxenite, gabbros, diabase dykes, sheeted dyke complex and basic volcanites are other constituents of the ophiolite. rocks samples and chromite ore sampleswere analyzed for $\mathrm{Pt}, \mathrm{Pd}, \mathrm{Rh}$ and $\mathrm{Au}$ using ICP-MS and for Ir and trace elements using
\end{abstract}

\footnotetext{
* Yazışmaların yapılacağı yazar: Gülşah ÖZEK, Elazığ Belediyesi, İşletme ve Işstirakler Müdürlüğü,

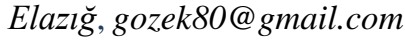


Neutron Activation Methods. The analytical data are normalized for primitive mantle and used in spider diagrams. These diagrams illustrate that the rocks have negative anomalies for $\mathrm{Rh}, \mathrm{Pt}$ is close to mantle values, $\mathrm{Pd}$ close or show enrichment and $\mathrm{Au}$ is enriched in comparison to the mantle. The PGE contents of ore samples vary. Ir shows positive anomaly, $\mathrm{Rh}$ negative, $\mathrm{Pt}$ and $\mathrm{Pd}$ are close to or richer, and $\mathrm{Au}$ is richer than the mantle values. Samples are determined as Irarsite, according to Ir ratio 45-550 wt $\%$ - Rh ratio of 0,05-5,56 wt \% - Pt ratio also 0,1-23 wt \% and Chromites have the asthenospheric composition with reference to PGE data.

Key Words: Guleman, Ophiolite, Podiform chromites, PGE (platinum group elements), Elazığ

\section{GíRiș}

İnceleme alanı, Elazı ğ ilinin yaklaşık $80 \mathrm{~km}$ GD'sunda ve Alacakaya ilçesi sınırları içinde yer almaktadır (Şekil 1). Guleman Bölgesinde birçok kayaç topluluğu bulunmaktadır. Bunları yaşlıdan gence Paleozoyik yaşlı Bitlis Metamorfitleri, Üst Kretase yaşlı Guleman Ofiyoliti, Üst Meastrihtiyen- Orta Eosen yaşlı Hazar Grubu, Orta Eosen yaşlı Maden Karmaşı̆̆ı ve Miyosen yaşlı Lice Formasyonu oluşturmaktadır. Alp-Himalaya orojenik sistemi içinde önemli bir yere sahip olan Türkiye, yaklaşık olarak D-B uzanımlı tektonik kuşaklar arasında (Pontidler, Anatolidler, Toridler ve Kenar kıvrımlar) Paleotetis ve Neotetis okyanusal basenlerinin kalıntılarını içermektedir [1-3]. Güneydoğu Anadolu'da kuzeydoğugüneybatı doğrultulu Türkiye, Kıbrıs ve Suriye'yi içine alan kuzey ve güney olmak üzere iki farklı ofiyolit kuşağının olduğu bilinmektedir [4-7].

Kuzeyde yer alan ofiyolit kuşağı, Toros platformu ile Bitlis-Pütürge masifi arasında yer alan Göksun, İspendere, Kömürhan, Guleman ve Killan ofiyolitlerini kapsamaktadır. Başpınar, 'Guleman (Elazığ) Bölgesi Krom Yataklarının Platin Grubu Element (PGE) içerikleri ve Jeokimyası' konulu bu çalışmada; ofiyolitik kütlenin petrografik ve jeokimyasal açıdan incelenmesi, bu kayaçlar içerisinde yer alan krom yataklarının ve yan kayaçlarının jeolojisi ve mineralojisinin incelenmesi, kromit ve yan kayaçlarının Platin Grubu Element (PGE) içerikleri tespit edilip elde edilen jeokimyasal verilerin değerlendirilmesi amaçlanmıştır.
Kromit yatakları yaklaşık $200 \mathrm{~km}^{2}$ 'lik bir alanı kaplayan Jura-Alt Kretase oluşum yaşındaki Guleman Ofiyoliti içerisinde podiform tipte geliştiği, Krom cevherleşmelerinin ofiyolitik birimin peridotitik kayaçlar (dünit, harzburjit) içerisinde yer aldığı daha önceki yıllarda bölgede yapılan genel jeoloji, petrografi ve tektonik ağırlıklı çalışmalarda değişik araştırmacılar tarafindan incelenmiştir.

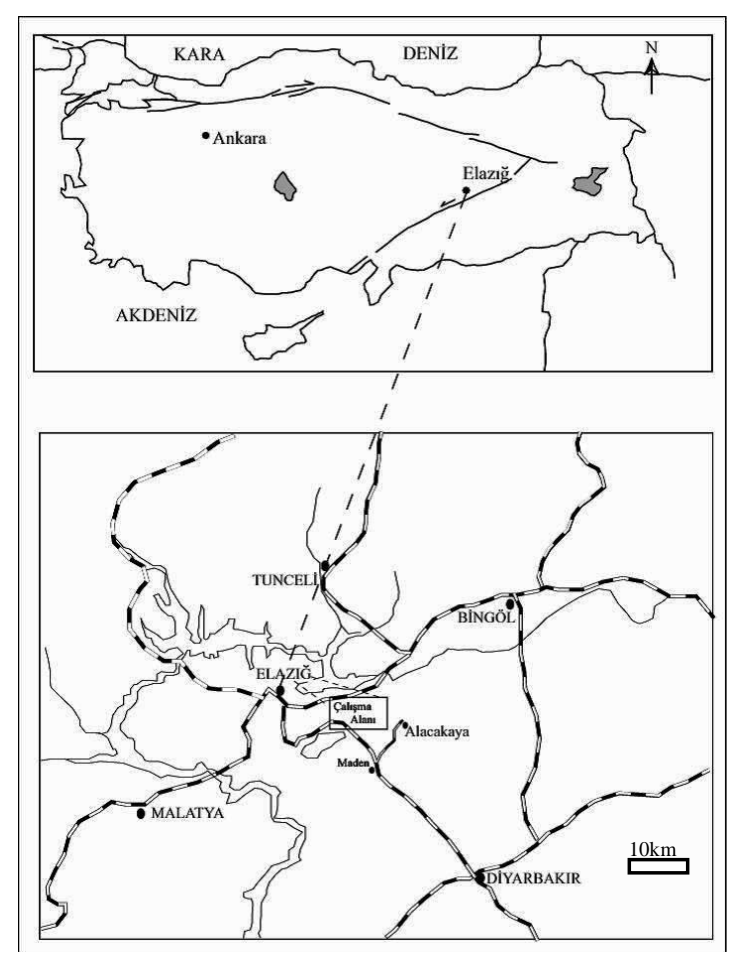

Şekil 1. Çalışma alanının yer bulduru haritası 
Ancak krom cevherleşmesinin platin grubu elementlerin araştırılmasına ait ayrıntılı bir çalışma bulunmamaktadır. Bu çalışma da bölgede yapılan çalışmalara ilaveten krom cevherleşmesinin Platin Grubu Elementler açısından incelenmesi amaçlanmıştır. Özkan (1982, 1983a, 1983b, 1984), Guleman ofiyoliti üzerinde yaptığı değişik amaçlı çalışmalarında, Guleman ofiyolitinin Güneydoğu Anadolu Tersiyer sürüklenim kuşağı içinde yer alan ultramafik-mafik kütlelerden biri olduğunu belirtmiş ve birimin tektonik dilimlenmeyle parçalanmış eksik bir ofiyolit topluluğunu temsil ettiğini belirtmektedir [8-10]. Page ve arkadaşları (1984), 'Guleman Bölgesi Batı Kef Kromit Yatakları Platin Grubu Elementlerin Dağılımı' adlı çalışması, Türkiye'deki ofiyolitlerin PGE içeriklerinin saptanması, bunun Batı Kef yatağındaki metallerle karşılaştırılması ve yine bu bulguların dünyanın diğer bölgelerinde ofiyolitlerin PGE içerikleriyle karşılaştırmak amacıyla yapılmıştır [11]. Engin ve Özkan (1985), Guleman bölgesinin yapısal durumunu ve peridotitlerin petrografisini incelemişler [12]. Bingöl (1986), Guleman ofiyolitinin petrografisini ve petrolojisi üzerine yaptığı çalışmalarda, bunların yüksek sıcaklıklarda plastik deformasyon geçirmiş tektonitler ve deforme olmamış kümülatlardan oluştuğunu ve İspendere Ofiyoliti'nin Guleman Ofiyoliti'nin batı uzantıs1 olduğunu kabul etmiştir [13]. Özsoy (2001), Ayıpınar krom cevherleşmesini incelemiş buradaki cevherleşmenin ortomagmatik evrede kristal eriyik farklılaşması ile okyanus ortası sırtlarda oluştuğu sonucuna varmıştır [14]. Örün (2002), Rut ve Lasir bölgesi krom yataklarının jeolojisi ve jeokimyasal özelliklerini incelemiştir [15]. Çelik (2003), 'Mastar Dağı (Elazı̆g GD'su) çevresinin stratigrafik ve tektonik özellikleri' konulu çalışmasında inceleme alanı içerisinde yer alan Hazar Karmaşı ̆̆ Ofiyolitini ayrıntılı bir şekilde incelemiştir [16]. Kılıç (2005), 'Hazar Gölü (Sivrice-Elazığ) Güneyinin Petrografik ve Petrolojik Özellikleri' konulu çalışmasında inceleme alanı içinde yer alan Guleman Ofiyolitlerini incelemiş ve bu ofiyolitde manto kayacı olarak harzburjitin olması, kalın ve değişik litolojide bir gabro seviyesinin bulunması Guleman Ofiyolitinin harzburjit tip ofiyolit (HOT) olduğunu, gerek harzburjitlerin varlığı gerekse jeokimyasal verilere dayanarak Guleman Ofiyolitinin bir Supra-Subduction tip ofiyolit olduğunu belirtmiştir [17].

\section{GENEL JEOLOJI}

İnceleme alanında birçok kayaç topluluğu bulunmaktadır (Şekil 2, 3). İnceleme alanında kayaçlar geniş çerçevede incelendiğinde başlıca iki yapısal birime ayrilabilmektedir. Bunlardan Lice Formasyonu ve Bitlis Metamorfitleri otokton, Guleman Grubu, Hazar Karmaşığı ve Maden Karmaşı̆̆ı ise allokton birimlerdir. Bitlis Metamorfitleri Guleman Ofiyolitleri üzerine tektonik dokanakla gelmektedir. Hazar Karmaşı ğ ve Maden Karmaşığı bu birimi uyumsuz olarak örtmekte ve bu birimler Alt Miyosen yaşlı Lice Formasyonu üzerine bindirmişlerdir (Şekil 3).

\subsection{Litoloji}

Guleman Ofiyoliti; başlıca dünit ve kromitit içeren harzburjitlerden oluşan tektonitler ile bunların üzerine açılı uyumsuzlukla gelen dünit, verlit, klinopiroksenit, tabakalı gabrolardan oluşan kümülatlar, tüm bu birimleri kesen tekil diyabaz daykları ile ve bazik volkanik kayaçlardan oluşmaktadır (Şekil 4-8). Tektonitler inceleme alanında daha çok krom cevherleşmelerinin yer aldığ 1 Sori bölgesinde görülmektedir. Başlıca harzburjit ve dünitten oluşur ve dünitlerin harzburjitlere gore bağıl miktarları daha azdır. Ultramafik tektonitler, sadece manto sicaklık ve basınç koşullarında oluşabilen plastik deformasyon, kısmi ergime ve rekristalizasyon yapı ve dokularını gösterirler [8].

Kümülatlar tektonitleri çevreler konumda olup Baltaşı (Nacaran) köyü civarında ve inceleme alanının batısında yer almaktadır (Şekil 1). Tektonitlerin üzerinde dünitlerle başlayıp harzburjit, gabrolara kadar uzanan ve kristal çökelimi süreciyle oluştuklarını belgeleyen tipik yap1 ve dokular sunan kümülatlar grubu kayaçlar, 2800 m kalınlığında bir magmatik seri olup kristal yerleşme proseslerine katkıda bulunan yap1 ve dokular gösterirler [9]. Bazik volkanik kayaçlar ise 




Şekil 2. Guleman bölgesinin jeoloji haritası [9]

inceleme alanında Caferi köyü yakınlarında yüzeylemektedir (Şekil 1).

\subsubsection{Yaş}

Özkan (1982), Guleman Ofiyoliti üzerine yaptığı çalışmalar sonucu birime Üst Jura-Alt Kretase [8], Bingöl (1984, 1986) Geç Jura-Erken Kretase [13, 18], Sungurlu (1979), Elazığ-Hazar-Palu çevresinde yaptıkları çalışmalarda Guleman Grubu'nda ilk kez rastladıklarını belirttikleri volkanitlerle girik olarak gözlenen kırmızı renkli kireçtaşlarından almış oldukları kayaç örneklerinde Globotruncana sp., Globotruncana stuarti,
Globotruncana lapparenti, Globotruncana arca ve Heterohelix sp. fosillerini tespit ederek Kampaniyen-Alt Maastrihtiyen yaşını birim için önermişlerdir [19]. Kılıç (2005), inceleme alanının batısında birim üzerine yaptığı çalışmada; Guleman Ofiyoliti'nin Neotetis'in güney kolunun, Üst Kretase' de kuzeye doğru dalmasiyla, dalan kabuk üzerindeki okyanusal kabukta meydana gelen açılmaya bağlı olarak gelişen okyanus kabuğu ürünleri olduğu belirlenmiş ve dolayısıyla da yaşının Üst Kretase olması gerektiği belirtmektedir. Yapılan bu çalışmada Guleman Ofiyolitinin yaşı için Üst Jura-Alt Kretase yaşı benimsenmiştir [17]. 




Şekil 3. Guleman bölgesinin genelleştirilmiş tektonostratigrafik kesiti [20].

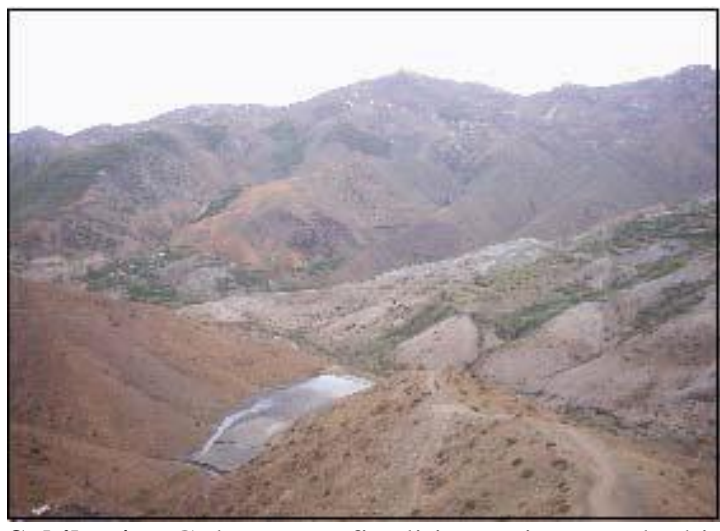

Şekil 4. Guleman ofiyolitine ait genel bir görünüm. Bakıș yönü batı Kef tepeden kuzeydoğuya doğrudur.

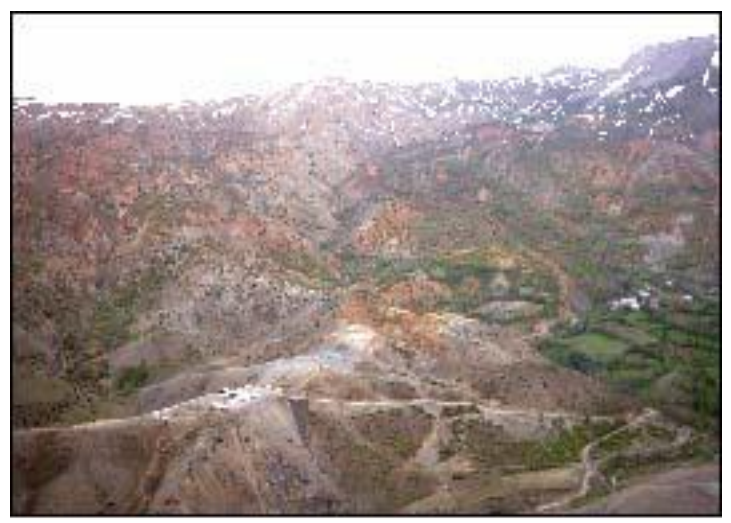

Şekil 5. Guleman ofiyolitine ait genel bir görünüm. Bakış yönü Batı Kef tepeden doğuya doğrudur.

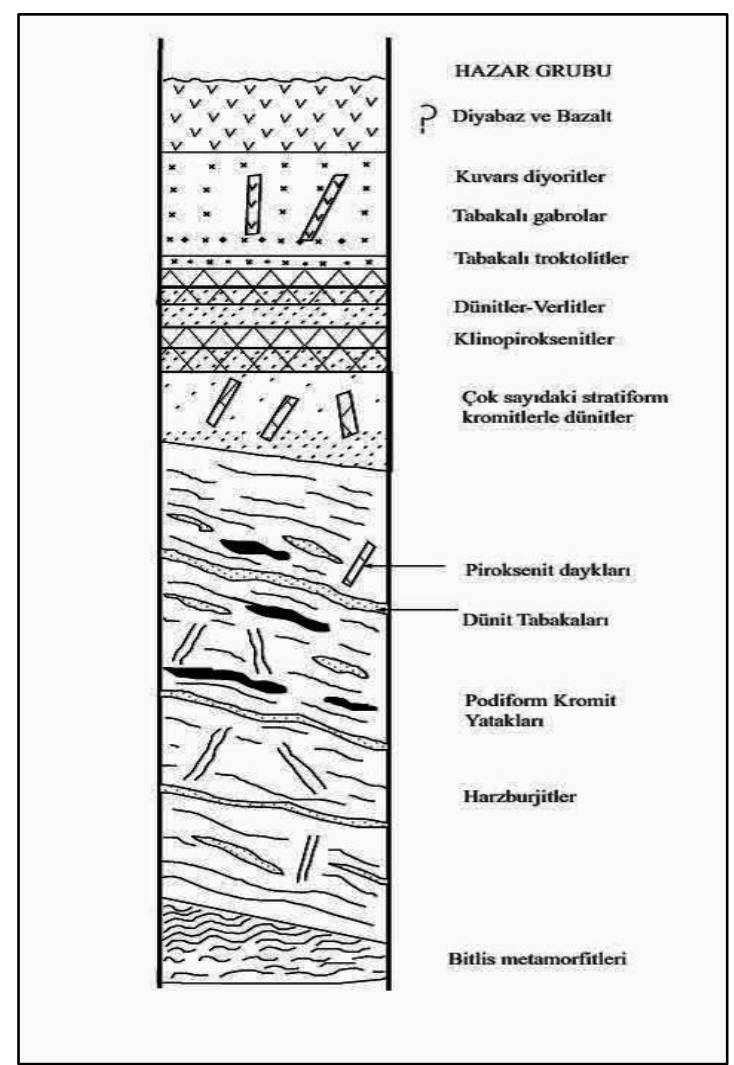

Şekil 6. Guleman ofiyolitinin genelleştirilmiş bölgesel kesiti ([13]'den değiştirilerek). 


\subsubsection{Petrografi}

\subsubsection{Tektonitler}

Tektonitler inceleme alanında dünit ve harzburjit litolojisinde izlenmektedir. Bu kayaçlar daha çok krom cevherleşmesinin yer aldığı Sori bölgesinde yaygın olarak görülmekte ve arazide yeşilimsi sarı renkte, bol kırıklı, çatlaklı bir görünümdedirler.

Dunitler; granuler ve elek doku sunmakta ve \%90-92 oranında olivin, \%3-4 ortopiroksen ve eser miktarda serpantin minerallerinden oluşmaktadırlar (Şekil 7a,b). Harzburjit türü kayalar ise granuler, poikilitik, elek doku göstermekte, yaklaşık \%50-60 oranında olivine, \%30-35 ortopiroksen, \%5-7 ojit, \%1-2 serpantin ve \%1-2 oranında kromit minerallerinden oluşmaktadırlar (Şekil 7c).

\subsubsection{Kümülatlar}

İnceleme alanında kümülat grubu kayaçlar başlıca; dünit, verlit, klinopiroksenit, olivinli gabro, gabro tüm bu birimleri kesen tekil diyabaz daykları, levha dayk karmaşığı ve bazik volkanik kayaçlardan oluşur. Dunitler; granuler doku sunmaktadırlar ve yaklaşık olarak \%70-92 oranında olivin, \%5-20 oranında krom kristalleri ve eser miktarda serpantin mineralleri içermektedirler (Şekil 8). Çalışma alanında izlenen verlit türü kayalar; Olivinler kayacın yaklaşık \%65-70'ini olușturup genellikle özşekilsiz kristaller halinde izlenmekte, Klinopiroksenler kayacın yaklaşık olarak \%25-30'unu oluşturup yarı özşekilli ve özşekilsiz kristaller halinde bulunmakta ve ojit türü minerallerden oluşmaktadırlar yine bu kayaçlar içerisinde iz miktarda ortopiroksen, krom ve serpantin türü minerallere rastlanmıştır. Klinopiroksenitler ise granüler dokuya sahip, \&87-92 oranında ojit türü mineraller, \%4-6 olivin, \%3-4 oranında ortopiroksen ve iz miktarda krom minerallerinden meydana gelmektedirler (Şekil $7 \mathrm{~d}$,e, f). Olivinli gabrolar yaklaşık olarak \%50-60 plajiyoklas, \%40-50 klinopiroksen ve \%10'dan az olivinden oluşurlar. Kümülüs fazı oluşturan plajiyoklaslar, özşekilsiz ve yarı özşekilli kristaller halindedir (Şekil 8 a).
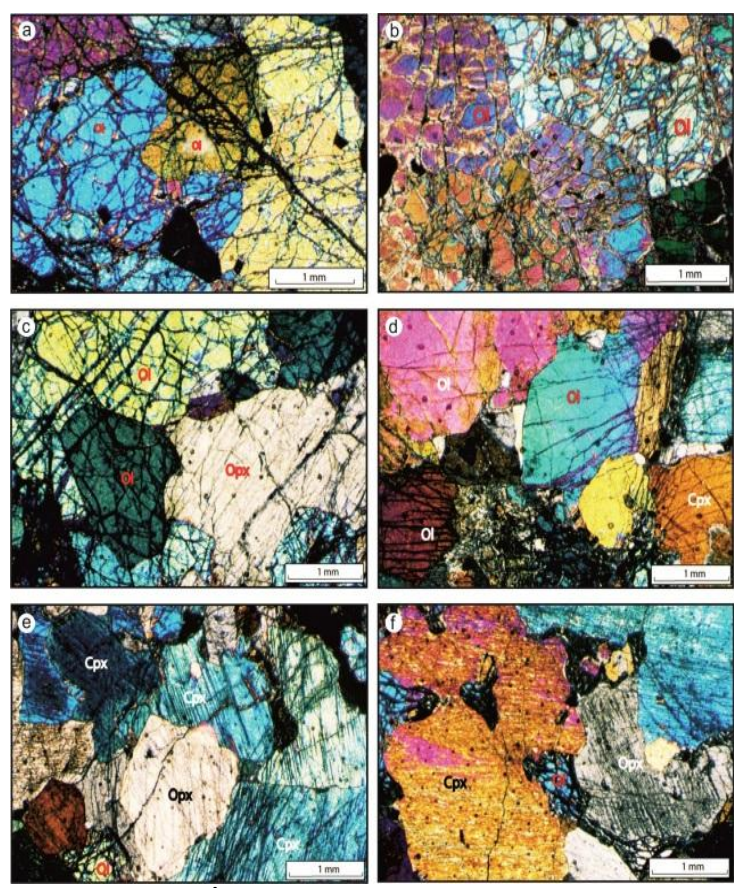

Şekil 7. a) İri kristalli öz şekilsiz olivinlerin mikroskopta görünümü, b) parçalanmıș olivinlerin mikroskopta görünümü, c)Tektonitlere ait harzburjitlerin mikroskopta görünümü, (d) Kümülatlara ait verlitin mikroskopta görünümü, (e) Adkümülat doku gösteren klinopiroksenitin mikroskopta görünümü, (f) Mezokümülat doku gösteren klinopiroksenitin mikroskopta görünümü. Cpx: Klinopiroksen, Opx: Ortopiroksen, Ol:olivin Ç.N X 32.

Gabrolar ise granuler-poikilitik doku sunmaktadırlar ve ortalama \%40-50 klinopiroksen, \%50-60 plajiyoklasdan oluşmuş kayaçlardır. İnceleme alanından derlenen diyabazlar ise tekil diyabaz daykları ve levha dayk karmaşığı şeklinde bulunmaktadır ve \%60-70 plajiyoklas, \%20-30 klinopiroksen ve \%10 civarında da amfibol ve klorit, epidot gibi ikincil minerallerden oluşmuştur (Şekil 8 b).

İnceleme alanında diyabazlar; tekil diyabaz daykları şeklinde bulunmaktadır. Tekil diyabaz dayklar arazide bej ile koyu gri renk tonlarında görülmektedir. Esas olarak plajiyoklas ve 
piroksenden daha az oranlarda amfibol, olivin, epidot minerallerinden meydana gelmiştir. Tekil diyabaz daykları; \%60-70 plajiyoklas, \%20-30 klinopiroksen ve \%10 civarında da amfibol ve klorit, epidot gibi ikincil minerallerden oluşmuştur (Şekil $8 \mathrm{c}, \mathrm{d}, \mathrm{e}$ ).

Bazaltlar Guleman Grubunun en üst kısımlarını oluşturmaktadır. Bu kayaçlarda mikrolitik porfirik doku izlenmekte hakim mineral plajiyoklaslarla temsil edilmektedir. \%20-25 oranında piroksen, \%15-17 oranında olivin izlenen kayaçlarda eser miktarda epidot, kalsit türü mineraller bulunmaktadır (Şekil 8f, g, h).

\section{GULEMAN OFIYOLITININ VE KROMLARIN PGE İÇERİĞİ}

\subsection{PGE'lerin Jeokimyası}

Birbirine benzer fiziksel ve kimyasal özellikler gösteren, rutenyum (44Ru), rodyum (45Rh), palladyum (46Pd), osmiyum (760s), iridyum (77Ir) ve platin (78Pt)'den oluşan ve periyodik cetvelde VIII A grubunda yer alan elementler platin gurubu elementler (PGE) olarak adlandırilırlar. Bu çalışmada 8 adet kayaç örneği (dünit, harzburjit, piroksenit, gabro) ve 20 adet kromit örneği Canada ACME analitik laboratuarlarında analiz edilmiştir.

Analizlerde Pt, Pd, Rh ve Au için ICP-MS yöntemi, Ir ve kromitlerin iz element içerikleri için ise nötron aktivasyon yöntemi kullanılmıştır. $\mathrm{Bu}$ analiz sonuçları Çizelge 1'de verilmiştir.

Guleman ofiyoliti çok değişken PGE içeriği ve oranlarını gösterir. Örneğin $\mathrm{Rh}$ kayaçlarda 0,05 ppb'lerde seyrederken krom örneklerinde 0,05 ppb'den 5,56 ppb'ye çıkmakta, Pt kayaçlarda $0,9 \mathrm{ppb}$ ila $17,3 \mathrm{ppb}$ iken krom örneklerinde 0,1 $\mathrm{ppb}$ ila 19,6 ppb arasında değişmekte, Pd kayaçlarda 1,6 ppb ile 16,2 ppb arasında iken krom örneklerinde 0,5 ila 29,3 ppb arasında, Ir ise kromlarda 24 ppb'lerden 440 ppb'ye çıkmaktadır (Şekil 9). Guleman ofiyotinin $\mathrm{Au}$ içeriği kayaçlarda 2 ppb ile 7 ppb arasında değişmekte
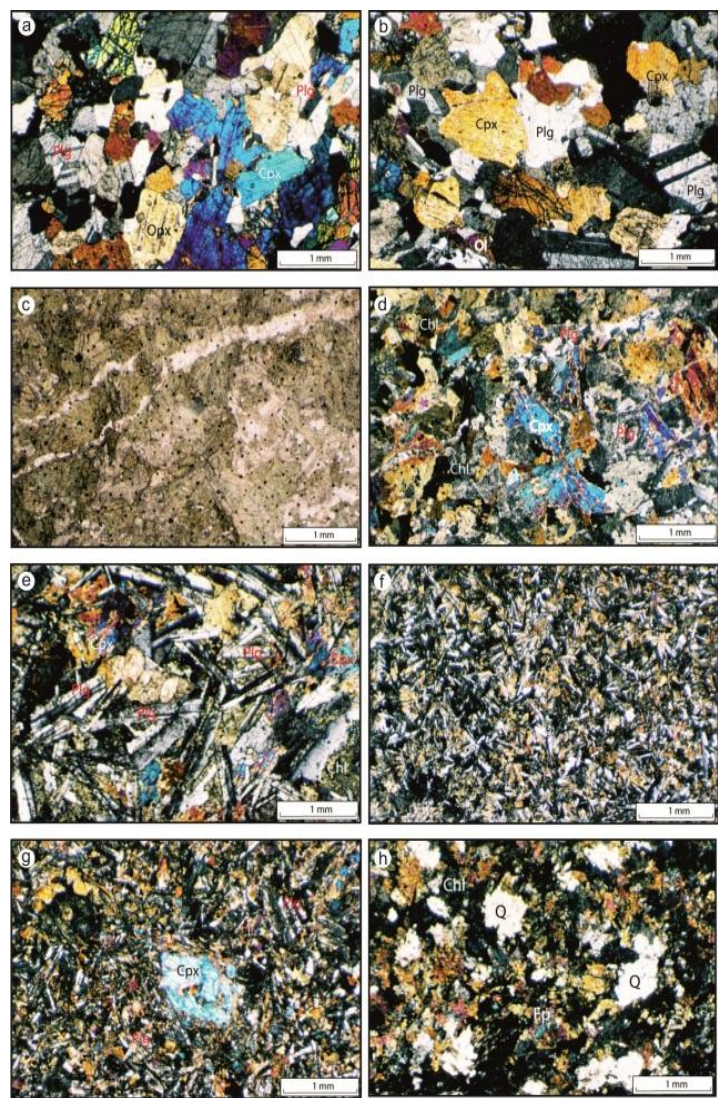

Şekil 8. a)Kümülatlara ait gabroların mikroskobik görünümü, b) mezokümülat doku gösteren klinopiroksenli gabroların mikroskobik görünümü, c) tekil diyabazların tek nikol mikroskobik görünümü, d) tekil diyabazlarda görülen intergranüler dokunun mikroskobik görünümü., e) tekil diyabaz dayklarında görülen intergranüler dokunun mikroskobik görünümü, f), bazaltlarda görülen intersertal dokunun mikroskobik görünümü. g), bazaltlarda görülen mikroporfirik dokunun mikroskobik görünümü. h) bazaltlarda alterasyon sonucu gelişen epidot, klorit, ikincil kuvarslar. Ol: olivin, Opx: ortopiroksen, Cpx: klinopiroksen, Plg: plajiyoklaz, Chl: klorit, Ep: epidot, Q: ikincil kuvars. Çift nikol X 32. 
Elazı̆̆ Bölgesi Kromitit ve Yan Kayaçlarına ait PGE Içerikleri ve Jeokimyasal Yorumu

Çizelge 1. Guleman ofiyolitine ait kayaç ve krom örneklerinin PGE ve bazı element içerikleri

\begin{tabular}{|c|c|c|c|c|c|c|c|c|c|c|c|c|c|c|}
\hline & $\begin{array}{c}\text { Õm. } \\
\text { no }\end{array}$ & $\mathrm{Cr}$ & Pt & $\mathrm{Pd}$ & $\mathrm{Rh}$ & Ir & $\begin{array}{l}\mathrm{Pd} / \\
\mathrm{Ir}\end{array}$ & $A \mathbf{u}$ & $\mathrm{Ni}$ & $\mathrm{Co}$ & $\mathrm{Cu}$ & $\mathrm{Zn}$ \\
\hline & & & & $\%$ & \multicolumn{5}{|c|}{$\mathrm{ppb}$} & \multicolumn{5}{|c|}{ ppm } \\
\hline \multicolumn{3}{|c|}{ lksel Manto Değeri } & & & 8,3 & 4,4 & 1,6 & 4,4 & 1,00 & 1, & & & & \\
\hline \multirow{8}{*}{$\begin{array}{l}0 \\
4 \\
4\end{array}$} & & \multirow{2}{*}{ Harzburjit } & 2 & 0,833 & 10,7 & 10,3 & 0,05 & - & - & 7 & 2149 & 110 & 15 & 33 \\
\hline & & & 3 & 1,146 & 8,7 & 5,4 & 0,05 & - & - & 4 & 2227 & 116 & 7 & 32 \\
\hline & & \multirow{2}{*}{ Dünit } & 7 & 1,047 & 8,8 & 8,5 & 0,05 & $=$ & - & 5 & 1919 & 112 & 17 & 34 \\
\hline & & & 15 & 0,513 & 8,3 & 7 & 0,05 & - & - & 2 & 2227 & 113 & 5 & 31 \\
\hline & & \multirow{2}{*}{ Gabro } & G-1 & 0,230 & 17,3 & 12,1 & 0,05 & - & - & 5 & 256 & 58 & 44 & 19 \\
\hline & & & G-2 & 0,230 & 0,9 & 1,6 & 0,05 & - & - & 4 & 165 & 55 & 22 & 26 \\
\hline & & \multirow{2}{*}{ Piroksenit } & P.1 & 0,694 & 16.3 & 16,2 & 0.05 & $=$ & - & 3 & 239 & 46 & 6 & 8 \\
\hline & & & P. 2 & 0,414 & 2,7 & 8,5 & 0,05 & $=$ & $=$ & 4 & 218 & 59 & 33 & 36 \\
\hline & \multirow{10}{*}{ 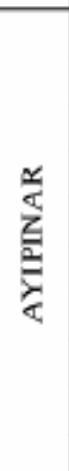 } & \multirow{2}{*}{ Tenkella } & $\mathrm{CA} \cdot 5$ & 34 & 2 & 6 & 0,05 & 50 & 0,12 & 2 & 2100 & 187 & - & 300 \\
\hline & & & CA.9 & 36 & 2,7 & 5,4 & 0,05 & 99 & 0,05 & 2 & 2100 & 181 & - & 240 \\
\hline & & \multirow{2}{*}{$\begin{array}{l}\text { Ayı } \\
\text { Damar }\end{array}$} & CA. 13 & 38 & 8,4 & 15,4 & 1,5 & 230 & 0,07 & 2 & 1200 & 203 & $=$ & 380 \\
\hline & & & CA: 17 & 42 & 3,5 & 5,7 & 0,05 & 110 & 0,05 & 1 & 1600 & 215 & $=$ & 280 \\
\hline & & \multirow{2}{*}{$\begin{array}{l}\text { Uzun } \\
\text { Damar I }\end{array}$} & $\mathrm{CA} \cdot 24$ & 30 & 1,4 & 6,4 & 0,05 & 86 & 0,07 & 9 & 1800 & 166 & - & 260 \\
\hline & & & CA.27 & 28 & 2,2 & 6,2 & 0,79 & 99 & 0,06 & 6 & 1600 & 170 & - & 270 \\
\hline & & \multirow{2}{*}{$\begin{array}{l}\text { Uzin } \\
\text { Damar II }\end{array}$} & CA. 32 & 34 & 4,2 & 5,6 & 0,05 & 83 & 0,06 & 3 & 1100 & 184 & - & 310 \\
\hline & & & CA.39 & 33 & 2,4 & 5,5 & 0,05 & 110 & 0,05 & 5 & 1500 & 200 & $=$ & 300 \\
\hline & & \multirow{2}{*}{ Tepebaşı } & CA-4I & 34 & 19,1 & 24 & 0,93 & 160 & 0,15 & 4 & 1600 & 185 & . & 240 \\
\hline & & & CA.46 & 36 & 5.7 & 5 & 0.05 & 170 & 0.03 & 8 & 1700 & 196 & - & 250 \\
\hline \multirow{5}{*}{ 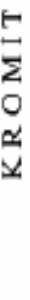 } & \multirow{3}{*}{$\frac{z}{z}$} & & CK-1 & 38 & 23 & 29,3 & 1,69 & 130 & 0,22 & 21 & 3000 & 219 & . & 280 \\
\hline & & & $\mathrm{CK} \cdot 2$ & 36 & 15 & 25,6 & 0,94 & 230 & 0,11 & 47 & 2200 & 194 & - & 280 \\
\hline & & & $\mathrm{CK} \cdot 3$ & 37 & 19,6 & 13,6 & 0,83 & 120 & 0,11 & 7 & 1700 & 207 & - & 360 \\
\hline & \multirow{2}{*}{ 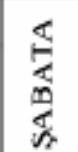 } & & CS-1 & 35 & 8,4 & 7 & 5,56 & 440 & 0,02 & 4 & 1400 & 187 & - & 280 \\
\hline & & & $\mathrm{CS}-2$ & 35 & 2 & 5,1 & 3,98 & 80 & 0,07 & 12 & 1600 & 176 & - & 230 \\
\hline & \multirow{3}{*}{ 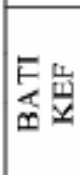 } & & CB-1 & 24 & 0,1 & 0,5 & 1,68 & 45 & 0,01 & 1 & 2300 & 180 & 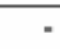 & 210 \\
\hline & & & $\mathrm{CB}-4$ & 31 & 0,8 & 0,8 & 1,96 & 50 & 0,02 & 2 & 2400 & 187 & - & 270 \\
\hline & & & CB-7 & 16 & 0,2 & 0,5 & 0,06 & -24 & $0, \overline{2}$ & 1 & 2300 & 163 & - & 230 \\
\hline & \multirow{2}{*}{ 总岃 } & & CD. 2 & 33 & 2,1 & 3,3 & 0.10 & 110 & 0,03 & 3 & 1600 & 200 & - & 380 \\
\hline & & & $\mathrm{CD} \cdot 3$ & 38 & 1,5 & 1 & 0,85 & 110 & 0,01 & 2 & 1800 & 225 & - & 350 \\
\hline
\end{tabular}


iken krom örneklerinde 1 ppb'den 47 ppb'ye birimin Ni içeriği ise kayaçlarda 218 ppm ile 2227 ppm arasında, krom örneklerinde ise 1100 ppm'den 2400 ppm'e çıkmaktadır (Çizelge 1).

Ir oranı 45-440 arasında değişmekte, $\mathrm{Rh}$ oranı 0,05-5,56 arasinda ve $\mathrm{Pt}$ oranı ise 0,1 ile 23 arasındadır ve örneklerin Irarsit olduğu belirlenmiştir (Şekil 9).

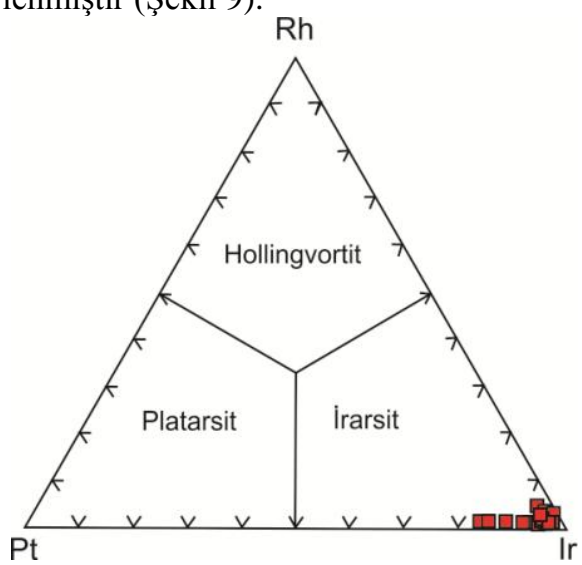

Şekil 9. $\mathrm{Ru}-\mathrm{Rh}-\mathrm{Ir}$ üçlü diyagramı

Kromitlere ait $\mathrm{Pd} / \mathrm{Ir}$ 'e karşı $\mathrm{Pt} / \mathrm{Pt}^{*} \quad\left(\mathrm{Pt} / \mathrm{Pt}^{*}\right.$ $[\mathrm{Pt} / 1020 /(\mathrm{Rh} / 200) \times(\mathrm{Pd} / 545) 1 / 2) \quad[21]$ diyagramı incelendiğinde kromitlerin astenosferik komposizyona sahip oldukları gözlenmiştir (Şekil 10).

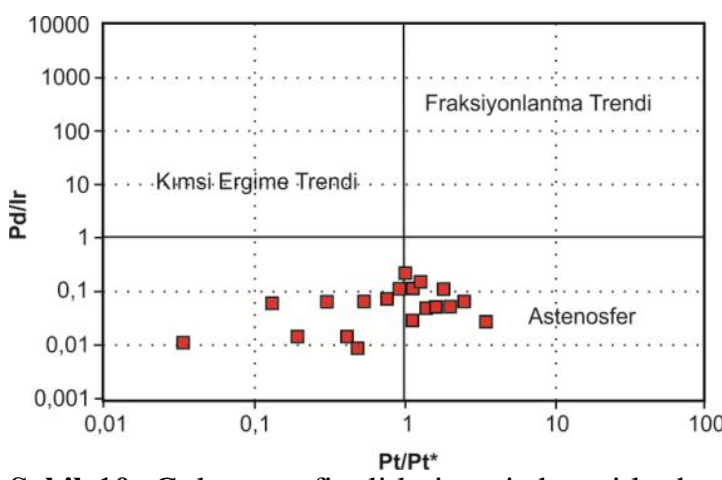

Şekil 10. Guleman ofiyolitlerine ait kromitlerden hazırlanmış $\mathrm{Pd} / \mathrm{Ir}$ ' e karşı $\mathrm{Pt} / \mathrm{Pt}^{*}$ diygaramı Fraksiyonlanma ve kısmi ergime trandleri Garuti et al. (1997)'den alınmıştır [21].
Elde edilen analiz sonuçları ilksel manto değerlerine göre normalleştirmiş ve sonuçlar spider diyagramlarında kullanılmıştır (Şekil 11) [22].

$\mathrm{Bu}$ sonuçlara gore dünit ve harzburjit PGE'lerce benzer davranıs göstermektedirler. Bu kayaçlarda $\mathrm{Rh}$ negatif bir anomali gösterip ilksel mantoya göre fakirleşmiştir. Pt ve $\mathrm{Pd}$ mantoya yakın değerler gösterirken, Au'nun mantoya göre zenginleştiği görülmektedir. Piroksenit ve gabrolar da PGE'lerce benzer davranış göstermektedirler. $\mathrm{Rh}$ yine negative bir anomali gösterirken, $\mathrm{Pt}$ piroksenit ve gabroların birer örneklerinde pozitif anomali gösterirken diğerlerinde negatif anomali göstermektedir. Pd piroksenitlerde ilksel mantoya gore zenginleşmişken, gabrolarda bir örnek mantoya göre fakirleşmiş bir örnekte mantoya gore zenginleşmiştir.

$\mathrm{Au}$ ise yine pozitif bir anomali göstermekte ve mantoya göre zenginleştiği görülmektedir. Tüm kayaçlar için yapılan diyagramda özetle; $\mathrm{Rh}$ negatif bir anomali göstermekte, Pt ve Pd mantoya yakın ve mantoya göre zenginleşmekte, $\mathrm{Au}$ ise yine mantoya göre zenginleştiği görülmektedir (Şekil 11). Pd ve Ir astenosferde aynı seviyede konsantrasyon olduklarından dolayı farklılaşmamış malzemenin $\mathrm{Pd} / \mathrm{Ir}$ oranı 1 civarında olması gerekir. $\mathrm{Pd} / \mathrm{Ir}$ oranı magma fraksiyonlaşmasında farklılaşma ile birlikte yükselir. Yani $\mathrm{Pd} / \mathrm{Ir}$ oranı arttıkça magma fraksiyonlaşması ilerlemiştir [21]. Guleman Ofiyolitine ait kayaçlarda Ir analizi yapılmamıştır. Fakat $\mathrm{Pd}$ değerleri dünit ve harzburjitten, piroksenit ve gabrolara doğru artmaktadır (Çizelge.1). Buda magmanın fraksiyonlaşması yada magma odasında kısmi ergime derecesinin artmasıyla ilişkilidir. $\mathrm{Ni} / \mathrm{Cu}$ oranı ise ters davranış şekli gösterir. İlksel manto $\mathrm{Ni} / \mathrm{Cu}$ değeri 71,4'dür. $\mathrm{Bu}$ değer magma kristalleşme fraksiyonlaşmasının artmasıyla azalır [21]. Guleman Ofiyolitine ait kayaçların $\mathrm{Ni} / \mathrm{Cu}$ oranı harzburjitlerde 200,73, dünitlerde 186,75, piroksenitlerde 11,83 , gabrolarda ise 6,35 'dir. $\mathrm{Bu}$ değerlerin dünit-harzburjit-piroksenit-gabrolara doğru gittikçe azaldığı görülmektedir. Buda magma fraksiyonlaşmasının artmasıyla $\mathrm{Ni} / \mathrm{Cu}$ oranının azaldığını göstermektedir [21]. 

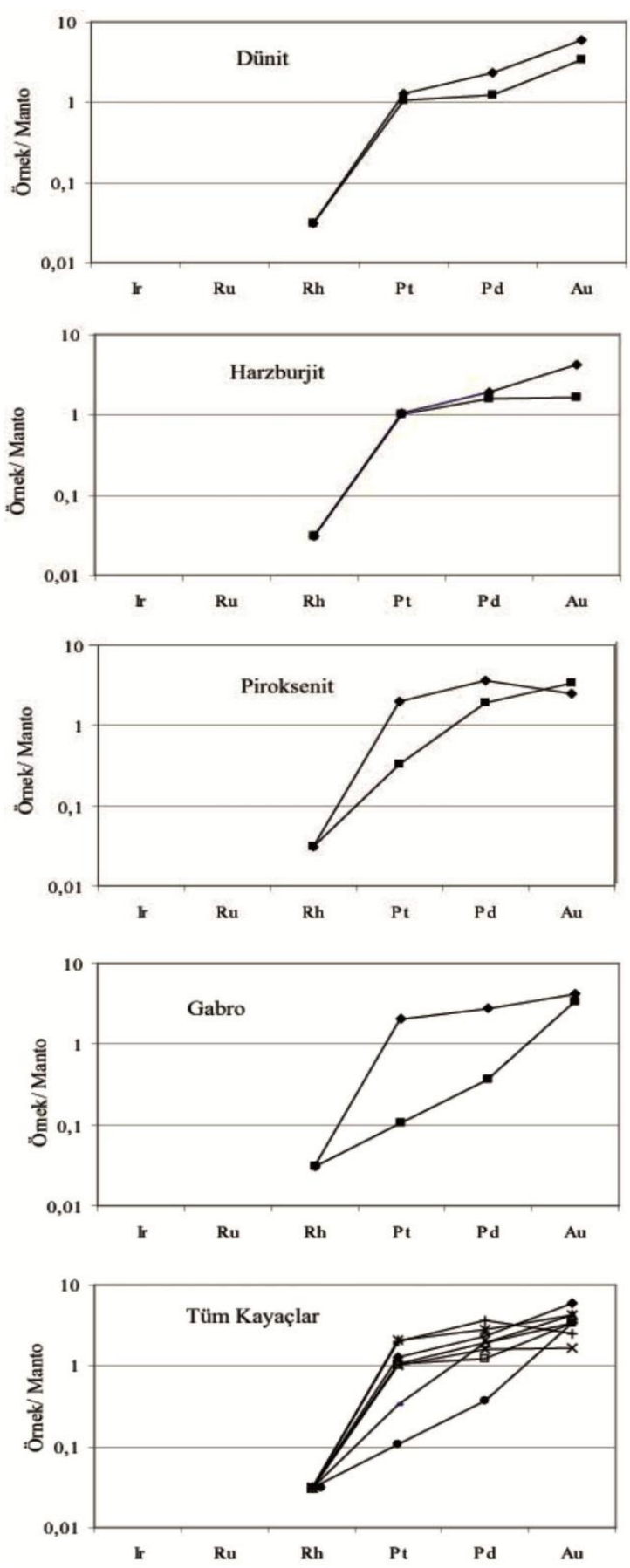

Şekil 11. Guleman Ofiyolitine ait dünit, harzburjit, piroksenitin, gabro ve tüm kayaçlar PGE spider diyagramları.
Krom örneklerinin PGE içerikleri de ilksel mantoya göre normalleştirilmiş ve sonuçlar spider diyagramlarında değerlendirilmiştir (Şekil 12). Buna göre Kapin bölgesinde, Ir ilksel mantoya göre 40-50 kat zenginleşmekte, $\mathrm{Rh}$ mantoya yakınlık gösterirken, $\mathrm{Pt}$ ve $\mathrm{Pd}$ mantoya göre zenginleşmekte, $\mathrm{Au}$ ise mantoya göre 40-50 katın üzerinde zenginleştiği görülmektedir (Şekil 12). Ayıpınar bölgesinde, Ir ilksel mantoya göre zenginleşmekte, $\mathrm{Rh}$ negatif anomali gösterip fakirleşmekte, Pt mantoya yakın ancak çoğu örnek negatif bir anomali göstermekte ve mantoya göre fakirleşmektedir. Pd mantoya yakın fakat çoğu örnekler mantoya gore zenginleşmekte ve $\mathrm{Au}$ ise yine mantoya göre zenginleşmektedir (Şekil 12).

Şabata bölgesinde, Ir ilksel mantoya göre 30-40, Rh 5-6 kat zenginleşmekte, Pt mantoya yakın ve mantoya göre fakirleşmekte, $\mathrm{Pd}$ mantoya yakın ve mantoya gore zenginleşmekte, $\mathrm{Au}$ ise yine mantoya göre zenginleşmektedir. Doğu ve batı Kef bölgelerinde, Ir, ilksel mantoya göre zenginleşmekte, $\mathrm{Rh}, \mathrm{Pt}, \mathrm{Pd}$ mantoya göre fakirleşmekte ve $\mathrm{Au}$ ise yine mantoya göre zenginleşmektedir. Tüm krom örnekleri için yapılan diyagramda; Ir, ilksel mantoya göre zenginleşmekte, Rh negatif bir anomali gösterip fakirleşmekte, Pt mantoya yakın ve mantoya göre fakirleşmekte, Pd mantoya yakın ve mantoya göre zenginleşmekte ve $\mathrm{Au}$ ise mantoya göre zenginleşmektedir (Şekil 12).

Pd-Ir ikili diygaramı incelendiğinde örneklerin meteoritik alana düştükleri, yine $\mathrm{Pt}$ ' ye karşılık Ir diyagramına gore örnekler kondritik alana düşmektedirler (Şekil 13).

\section{SONUÇLAR}

1. Yapılan petrografik çalışmalar sonucu Guleman Ofiyoliti'nin dünit, harzburjit, verlit, klinopiroksenit, olivinli gabro, klinopiroksenli gabro, bantlı gabro, tekil diyabaz dayklar, ile bazik volkanik kayaçlardan oluştuğu tespit edilmiştir.

2. Yapılan analiz sonuçlarına göre Guleman ofiyoliti çok değişken PGE içeriği ve oranlarını gösterir. Rh kayaçlarda 0,05 ppb'lerde seyrederken krom örneklerinde 5,56 ppb'ye, $\mathrm{Pt}$ 

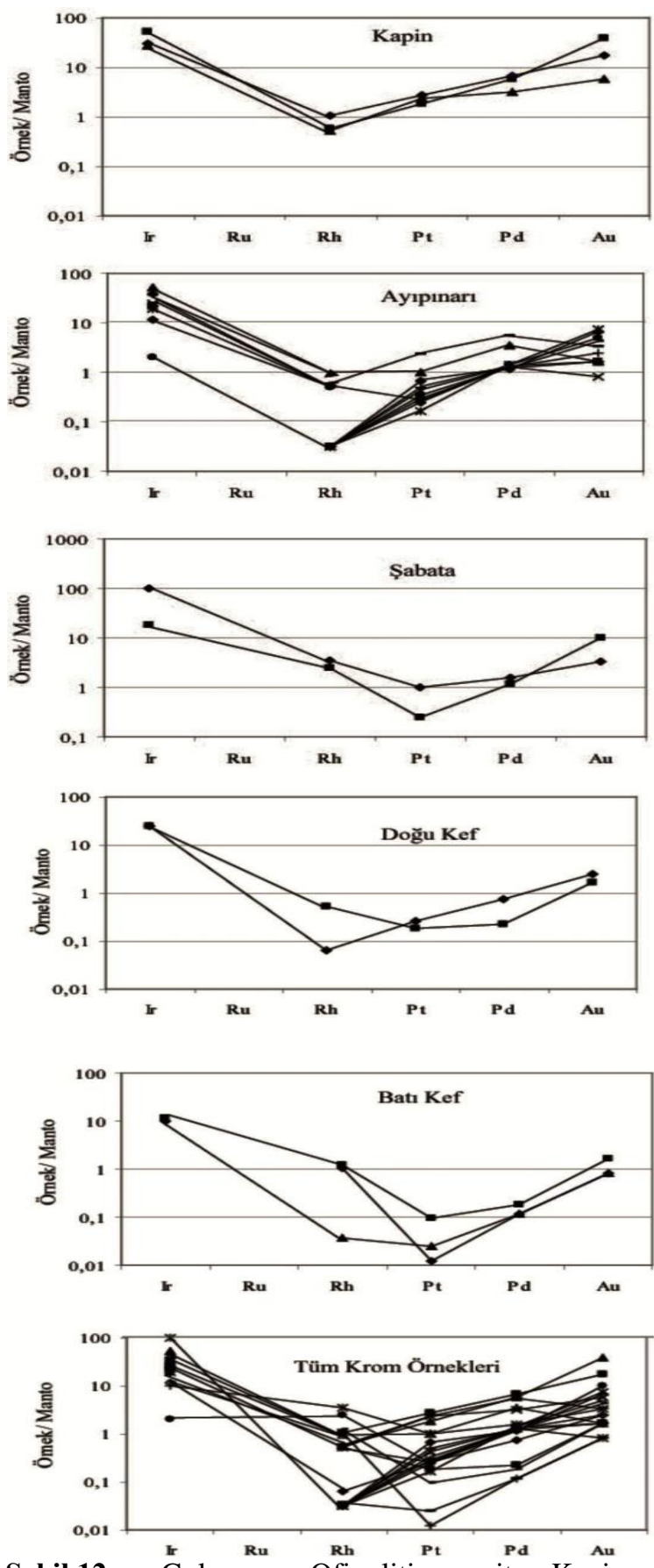

Şekil 12. Guleman Ofiyolitine ait Kapin, Ayıpınarı, Şabata, Doğu Kef, Batı Kef bölgeleri krom örnekleri ve tüm krom örneklerine krom örneklerinin PGE spider diyagramları

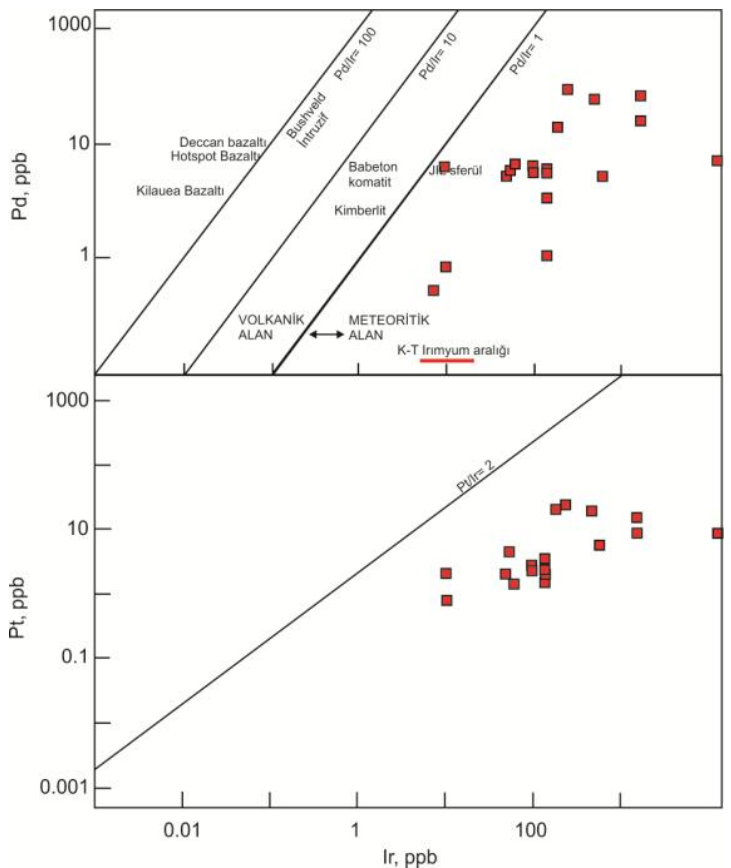

Şekil 13. Pd-Ir/ Pt-Ir ikili diyagramı [23-26].

kayaçlarda 17,3 ppb iken krom örneklerinde 19,6 ppb, Pd kayaçlarda 16,2 ppb krom örneklerinde 29,3 ppb arasında, Ir ise kromlarda 440 ppb'ye çıkmaktadır. Guleman ofiyolitinin $\mathrm{Au}$ içeriği kayaçlarda $7 \mathrm{ppb}$, krom örneklerinde 47 ppb’ye, $\mathrm{Ni}$ içeriği ise kayaçlarda 2227 ppm iken krom örneklerinde 2400 ppm'e çıkmaktadır.

3. Guleman ofiyolitine ait kayaçların analiz sonuçları ilksel manto değerlerine göre normalleştirmiş ve sonuçlar spider diyagramlarında kullanılmıştır. Tüm kayaçlar için yapılan diyagramda özetle; Rh negatif bir anomali gösterip ilksel mantoya göre fakirleşmekte, Pt ve Pd ilksel mantoya yakın ve ilksel mantoya göre zenginleşmekte, Au ise yine ilksel mantoya göre zenginleştiği görülmektedir.

4. Krom örnekleri de ilksel mantoya göre normalleştirilmiş ve sonuçlar spider diyagramlarında değerlendirilmiştir. Buna göre; Ir ilksel mantoya göre zenginleşmekte, $\mathrm{Rh}$ negatif bir anomali gösterip fakirleşmekte, Pt ilksel mantoya yakın ve ilksel mantoya göre 
fakirleşmekte, Pd ilksel mantoya yakın ve ilksel mantoya göre zenginleşmekte ve $\mathrm{Au}$ ise ilksel mantoya göre zenginleşmektedir.

5. Kromitlere ait $\mathrm{Pd} / \mathrm{Ir}$ 'e karş1 $\mathrm{Pt} / \mathrm{Pt}$ * $(\mathrm{Pt} / \mathrm{Pt} * \quad[\mathrm{Pt} / 1020 /(\mathrm{Rh} / 200) \times(\mathrm{Pd} / 545) 1 / 2) \quad[21]$ diyagramı incelendiğinde kromitlerin astenosferik komposizyona sahip oldukları gözlenmiştir.

6. Ir oranı 45-440 arasında değişmekte, $\mathrm{Rh}$ oranı 0,05-5,56 arasinda ve Pt oranı ise 0,1 ile 23 arasındadır ve örneklerin Irarsit olduğu belirlenmiştir.

\section{TEŞEKKÜR}

Çalışma, Gülşah ÖZEK' e ait Guleman (Elazığ) Bölgesi Krom Yataklarının Platin Grubu Element İçerikleri ve Jeokimyası adlı yüksek lisans tezinden yararlanılarak hazırlanmıştır.

\section{KAYNAKLAR}

1. Ketin, L., 1983. Türkiye Jeolojisine Genel Bir Bakış, T. T. O. Maden Fak. Sayı: 1.259, Sayfa: 595.

2. Şengör, A.M.C., Yılmaz, Y., 1981. Tethyan Evolution of Turkey, a Plate Tectonic Approach. Tectonophysics, 75, 181-241.

3. Robertson A. H. F., Dixon J. E. 1984. In the Geological Evolution of the Eastern Mediterranean, Introduction: Aspects of the Geological Evolution of the Eastern Mediterranean, Geological Society, London, Special Publications

4. Yilmaz, Y. 1993. New Evidence and Model on the Evolution of the Southeast Anatolian Orogen. Bulletin of Geological Society of America 105, 251-271.

5. Robertson, A. H. F., 2002. Overview of the Genesis and Emplacement of Mesozoic Ophiolites in the Eastern Mediterranean Tethyan Region. Lithos, 65, 1-67.

6. Parlak, O., Rızaoğlu, T., Bağcı, U., Karaoğlan, F., Höck, V., 2009. Tectonic Significance of the Geochemistry and Petrology of Ophiolites in Southeast Anatolia, Turkey. Tectonophysics 473, 173-187.
7. Robertson, A., Parlak, O., Ustaomer, T., 2012. Overview of the Palaeozoic-Neogene Evolution of Neotethys in the Eastern Mediterranean region (Southern Turkey, Cyprus, Syria) Petroleum Geoscience. 18, 4, p. 381-404 $24 \mathrm{p}$.

8. Özkan, Y.Z., 1982. Guleman (Elazığ) Ofiyolitinin Jeolojisi ve Petrolojisi, Yerbilimleri Dergisi, 3-4 /6, 33-39.

9. Özkan, Y.Z., 1983. Guleman (Elazı̆̆) Ofiyolitinin Yapısal İncelenmesi. MTA Dergisi, 37, 78-85.

10. Özkan, Y.Z., Öztunalı, Ö., 1984. Petrology of the Magmatic Rocks of Guleman Ophiolite in the Geology of the Taurus Belt. International Symposium Proceedings, Maden Tetkik ve Arama Enstitüsü, Ankara, Turkey, 285-293.

11. Page, N., Engin, T., Singer, D. A., Haffty, J., 1984. Distribution of the Platinum Group Elements in the Bat1 Kef chromite deposit, Guleman-Elazığ Area, Eastern Turkey, Economic Geology, 79, 177-184.

12. Engin, T., Özkan, Y.Z., 1985. Late Chromite Development in the Guleman Ophiolite, Elazığ, Eastern Turkey, Geology the Realword I.M.M Dunham-Durham Reunion, 101-108.

13. Bingöl, A.F., 1986. Petrographic and Petrological Characteristics of Intrusive Rocks of Guleman Ophiolite (Eastern TaurusTurkey), Geosound, 13/14, 41-57.

14. Özsoy, S., 2001. Ayıpınarı (Guleman-Elazığ) Krom Cevherleşmesinin İncelenmesi, Frrat Üniversitesi Fen Bilimlei Enstitüsü,Yüksek Lisans Tezi, 52s, (yayımlanmamış).

15. Örün, H., 2002. Rut ve Lasir (Guleman-Elazığ) Bölgesi Krom Yataklarının Jeolojisi ve Jeokimyas1, Fırat Üniversitesi Fen Bilimleri Enstitüsü, Yüksek Lisans Tezi, 57s.

16. Çelik, H., 2003. Mastar Dağı (Elazığ GD’su) Çevresinin Stratigrafik ve Tektonik Özellikleri, F.Ü. Fen Bilimleri Enstitüsü, Doktora tezi (yayımlanmamış).

17. Kılıç, A.D., 2005. Hazar Gölü (Sivrice-Elazığ) Güneyinin Petrografik ve Petrolojik Özellikleri, F.Ü. Fen Bilimleri Enstitüsü, s:103, Doktora Tezi (yayımlanmamış).

18. Bingöl, A.F., 1984. Geology of Elazı̆g Area in the Eastern Taurus Region. In the Geology of the Taurus Belt. International Symposium 
Proceedings, Maden Tetkik ve Arama Enstitüsü, Ankara, Turkey, 209-216.

19. Sungurlu, O., 1979. GD Sürüklenim Kuşağ Tersiyer Sürüklenimleri: 33. T.J.K. Bilimsel ve Teknik Kurultayı Bildiri Özetleri, 121-122.

20. Erdoğan, B., 1982. Ergani-Maden Yöresindeki Güneydoğu Anadolu Ofiyolit Kuşağının Jeolojisi ve Volkanik Kayaçları, TJK Bülteni, $25,49-60$.

21. Garuti, G., Fershtater, G., Bea, F., Montero, P., Pushkarev, E.V., Zaccarini, F., 1997. PlatinumGroup Elements as Petrological Indicators in Mafic-Ultramafic Complexes of the Central and Southern Urals: Preliminary Results, Tectonophysics, 276, 181-194.

22. Rollinson, H.R., 1993. Using Geochemical Data: Evaluation, Presentation, Interpreatation, Longman Scientific \& Technical, 353, Newyork.

23. Glikson, A.Y., 2005. Geochemical and Isotopic Signatures of Archaean to Palaeoproterozoic Extraterrestrial Impact Ejecta/Fallout Units. Aus. J. Earth Sci., 52, 785-798.

24. Peucker-Ehrenbrink, B., Jahn, B. 2001 Rhenium-Osmium Isotope Systematics and Platinum Group Element Concentrations: Loess and the Upper Continental Crust. Geochem. Geophys, Geosys, G3 2001 GC 000 172.

25. H. Palme, H. O’Neill., 2007. Cosmochemical Estimates of Mantle Composition, in: H. D. Holland, K. K. Turekian (eds.) Treatise on Geochemistry Oxford, pp. 1-38.

26. Frei, R., Frei, KM., 2002. A Multi-Isotopic and Trace Element Investigation of the CretaceousTertiary Boundary Layer at Stevns Klint, Denmark-Inferences for the Origin and Nature of Siderophile and Lithophile Element Geochemical Anomalies, Earth and Planetary Science Letters, no. 203, pp. 691-708. 
